OPEN ACCESS

Edited by:

Jane McIntosh Cooper University of Houston, United States

Reviewed by: Katerina Plakitsi,

University of loannina, Greece Scott Weber

Brigham Young University, United States

*Correspondence: Mark J. Graham mark.graham@yale.edu

Specialty section: This article was submitted to

Teacher Education,

a section of the journal

Frontiers in Education

Received: 02 August 2020 Accepted: 09 November 2020 Published: 08 December 2020

Citation:

Wang C, Bauer M, Burmeister AR, Hanauer DI and Graham MJ (2020) College Student Meaning Making and Interest Maintenance During

COVID-19: From Course-Based Undergraduate Research Experiences (CUREs) to Science Learning Being Off-Campus and Online. Front. Educ. 5:590738 doi: 10.3389/feduc.2020.590738

\section{College Student Meaning Making and Interest Maintenance During COVID-19: From Course-Based Undergraduate Research Experiences (CUREs) to Science Learning Being Off-Campus and Online}

\author{
Cong Wang ${ }^{1}$, Melanie Bauer ${ }^{1}$, Alita R. Burmeister ${ }^{1}$, David I. Hanauer ${ }^{2}$ and \\ Mark J. Graham ${ }^{1 *}$
}

${ }^{1}$ STEM Program Evaluation \& Research Lab (STEM-PERL), Department of Ecology and Evolutionary Biology, Yale University, New Haven, CT, United States, ${ }^{2}$ Department of English, Indiana University of Pennsylvania, Indiana, PA, United States

In response to the outbreak of COVID-19 the national landscape of higher education changed quickly and dramatically to move "online" in the Spring semester of 2020. While distressing to both faculty and students, it presents a unique opportunity to explore how students responded to this unexpected and challenging learning situation. In four undergraduate STEM courses that incorporated course-based undergraduate research experiences (CUREs) - which are often focused on discovery learning and laboratory research - we had an existing study in progress to track students' interest development at five time points over the Spring 2020 semester. Via this ongoing study we were able to investigate how students stay engaged in their college science courses when facing unexpected challenges and obstacles to their learning. Longitudinal survey data from 41 students in these CURE courses demonstrated that students' situational interest dropped significantly when their CURE courses unexpectedly shifted from hands-on, discovery-based, and laboratory-based instruction to online instruction. Although we observed a dramatic decline in student interest in general after the CURE courses moved fully online, the decline rates varied across students. Students who were able to make meaningful connections between the learning activities and their personal or career goals were more likely to maintain a higher level of interest in the course. Implications for practice are discussed.

Keywords: COVID-19, course-based undergraduate research experience (CURE), meaning making, interest, higher education 


\section{INTRODUCTION}

With the outbreak of COVID-19 in the Spring semester of 2020 , the national landscape of higher education changed quickly and dramatically to move "online" with limited opportunity for advanced planning. While unprecedented in recent times for college and university students, this situation presents a unique and urgent opportunity to explore how students respond to unexpected and challenging learning situations.

For the Spring 2020 semester we originally designed a longitudinal study to track students within four coursebased undergraduate research experience (CURE) courses by measuring their interest development at multiple time points. Normally, CUREs are an excellent context in which to study student interest, as evidence suggests that CUREs benefit college students' STEM knowledge, motivation, and academic plans more than do traditional learning contexts (Graham et al., 2013; Dolan, 2016; Hanauer et al., 2017; Corwin et al., 2018). In response to the COVID-19 outbreak, however, all four CURE courses that we were investigating had to shift to online learning environments for the rest of the semester. Although we were not able to explore student interest development within CUREs over a regular semester like we originally planned, the circumstances presented us with a unique opportunity to explore how the interest levels of students enrolled in CUREs-which are often based in discovery learning and laboratory researchevolved in a newly online environment. Student interest is essential to consider when investigating learning experiences in CUREs because it is the basis for which these types of courses are purported to be more engaging. This is due to CUREs having more authentic research elements when compared to typical college science, especially traditional laboratory and lecture-based courses (Auchincloss et al., 2014). Additionally, the psychology and education literature has shown that both situational and individual interest positively impacts learning (Hidi and Renninger, 2006; Renninger, 2010). Situational interest refers to a temporary psychological state of heightened motivation characterized by increased attention, effort, and affect (Schraw and Lehman, 2001). In contrast, individual interest refers to an enduring predisposition to re-engage with a topic over time (Renninger, 2010).

Previous work on the impact of undergraduate research on interest has suggested student interest fluctuates over the course of a research experience. Hernandez et al. (2018) measured undergraduates' interest in STEM at the beginning, middle, and end of a formal, non-course mentored summer research program. They found that for some undergraduate researchers (those with a low level of project ownership) interest was elevated at the start of the experience, declined at the midpoint, and then rebounded to the original level by the end. A similar fluctuation in student interest could be posited for coursebased research-as occurs in CURE courses-conducted during a regular, uninterrupted academic year.

While there are a number of perspectives to view student interest development and maintenance, such as self-regulated learning (Wolters and Pintrich, 1998), the current study focuses on college students' tendency and capability of meaning making.
Meaning Making is a potential factor explaining why students perceive the learning environment differently even when they sit in the same classroom and study with the same teacher (Wang, 2019). Making meaningful connections between learning and personal goals has been shown to increase college science students' perceptions of value for the learning task which, in turn, leads to increases in their interest (Hulleman et al., 2010). For example, in an introductory college biology course students who articulated why course material was useful to them personally were more likely to achieve a higher course grade, enroll in another biology course, and persist in a STEM major, as compared to students who only summarized course material (Canning et al., 2018). More generally, Wang (2019) investigated the impact of meaningfulness on students' learning experiences through a survey of 263 undergraduate and graduate students. Correlational analyses indicated that students who reported being able to bring value to learning and make learning more relevant tended to view their learning experiences more positively, perceive higher- level of needs satisfaction, and show adaptive motivation (Wang, 2019).

The present investigation focused on two key research questions (RQs). First, how do rapid course changes due to COVID-19 affect CURE students' various feelings (specifically interest, challenge, frustration) about their learning experiences (RQ1)? Second, we asked what factors affected students' changes in situational interest (RQ2)? We focus on situational interest in the present study and consider it an outcome variable because it is sensitive to the changing activities and features as a course progresses (Hulleman et al., 2017) and therefore capable of capturing fluctuations in students' interest over a semester. In order to capture the range of impacts on students in the target courses, we also included the additional variables of situational challenge and frustration.

For the first research question (RQ1), we collected longitudinal student data from four CUREs in the STEM fields to explore how students' situational interest, challenge, and frustration change over a semester, especially after the courses have been moved fully online due to institutional policy changes prompted by COVID-19. In the current study, all four CURE instructors had to adjust their course activities and assessments in the middle of a semester due to COVID-19. For instance, instead of providing students with hands-on research experiences, two of the modified online-version CUREs focused on professional scientist activities, such as writing and presenting research/grant proposals. Although instructors did their best in incorporating students' opinions into the modifications of the course, the modified courses still differed from what the students had originally enrolled in-a hands-on, authentic laboratory-based research experience. Therefore, we expected to observe a significant decrease in student situational interest, and a significant increase in frustration after the rapid online transition due to COVID-19 (Hypothesis 1).

For the second research question (RQ2), based on the literature in educational psychology we proposed that meaning making would play a role in student interest development during the transition to online learning (Hypothesis 2), especially given the unexpected mid-semester transition in the courses. Although 
student interest in the CURE course would be expected to decline in general due to the unexpected online transition, it is possible that some students could maintain a high level of interest in the course if they were able to perceive the adjusted CURE course as relevant to their academic and career goals. Therefore, we also posited that positive student perspectives on online-transitioned CUREs would mediate the association between meaning making and situational interest (Hypothesis 3).

\section{MATERIALS AND METHODS}

\subsection{Participants}

Participants in the study were undergraduate students at a research university in the northeast United States. They were recruited from four semester-long CURE courses across three disciplines: biology, anthropology, and computer science. The course sizes ranged from 9 to 32 students. Students who enrolled in these courses were contacted at the beginning of the semester via email and invited to participate in a series of online surveys. Out of the 63 students enrolled in these four courses, 41 students agreed to participate and completed at least one online survey. Among the 29 students who provided demographic information, 14 students (48\%) identified as male and 15 students (52\%) identified as female. The average age of these participants was 19.42 years $(S D=1.47)$, most of whom were first-year and sophomore students (83\%). Fourteen participants (48\%) identified as White, followed by Asian $(n=13 ; 45 \%)$, Hispanic $(n=3 ; 10 \%)$, and Native American $(n=2 ; 7 \%)$. Students were offered nominal course participation credit (less than $1 \%$ of final grade) for completing the survey. In addition, students who completed the surveys and agreed to include their data in the study were entered into a lottery for an electronic gift card valued at $\$ 100$. This project was approved by the institution's IRB Human Subjects Committee.

\subsection{Procedures and Measures}

Student data was collected at 7 time points via online surveys administered with Qualtrics survey software. Table 1 presents an overview of the data collection process, including the research contexts, the variables measured, as well as the response numbers and rates. We have included all survey questions in the Supplementary Material.

\subsubsection{Initial Individual Interest (Time 1)}

At Time 1 (see Table 1), we used six items from the Initial Individual Interest Questionnaire (Harackiewicz et al., 2008) to assess students' interest. This served as a covariate when analyzing situational interest changes in the current study. These items were rated on a 7 -point scale $(1=$ not at all true of me, $7=$ very true of me). Sample items included: "I chose to take this class because I'm really interested in the topic." Internal consistency reliability was acceptable (Cronbach's alpha coefficient $=0.77$ ).

\subsubsection{Situational Interest, Challenge, and Frustration} (Times 2, 3, 4, 5, and 6)

In order to investigate the changes in student learning experiences across the semester, students' situational interest, perceived challenge, and perceived frustration were assessed at five time points occurring approximately every 2 weeks. Three items assessed students' current levels of interest. Scale points ranged from 1 "extremely low" to 7 "extremely high." Sample items included: "Rate your current level of interest in this class." Internal consistency was good for the measure of situational interest across the five time points (Cronbach's alpha coefficients ranged from 0.82 to 0.97 ). Single-item measures were used to assess students' current levels of challenge ("Rate how challenging the class is at the current moment") and frustration ("Rate how frustrating the class is at the current moment"), with the scale ranging from 1 "not enough" to 7 "too much." Therefore, internal consistency reliabilities for challenge and frustration were not available.

\subsubsection{Positive Perspective on Online-Transitioned CUREs (Times 5 and 6)}

In response to COVID-19, the four CURE courses that we investigated moved fully online at Week 9 of the 15week semester. To understand students' perspectives on the unexpected changes in their courses, we asked students to

TABLE 1 | Overview of data collection.

\begin{tabular}{|c|c|c|c|c|c|c|c|}
\hline & $\begin{array}{c}\text { Time } 1 \\
\text { (week 3) }\end{array}$ & $\begin{array}{c}\text { Time } 2 \\
\text { (week 4) }\end{array}$ & $\begin{array}{c}\text { Time } 3 \\
\text { (week 6) }\end{array}$ & $\begin{array}{c}\text { Time } 4 \\
\text { (spring break) }\end{array}$ & $\begin{array}{c}\text { Time } 5 \\
\text { (week 11) }\end{array}$ & $\begin{array}{c}\text { Time } 6 \\
\text { (week 14) }\end{array}$ & $\begin{array}{c}\text { Time } 7 \\
\text { (week 15) }\end{array}$ \\
\hline Individual interest & $x$ & & & & & & \\
\hline Situational interest & & $x$ & $x$ & $x$ & $x$ & $x$ & \\
\hline Situational challenge & & $x$ & $x$ & $x$ & $x$ & $x$ & \\
\hline Situational frustration & & $x$ & $x$ & $x$ & $x$ & $x$ & \\
\hline \multicolumn{8}{|l|}{ Positive perspectives on } \\
\hline online-transitioned CUREs & & & & & $x$ & $x$ & \\
\hline Response numbers & 32 & 28 & 35 & 24 & 27 & 27 & 29 \\
\hline Response rates & $51 \%$ & $44 \%$ & $56 \%$ & $38 \%$ & $43 \%$ & $43 \%$ & $46 \%$ \\
\hline
\end{tabular}

Shift online at Time 4. Shift to Pass-Fail grading system at Time 5. 
comment on the online version of their CURE courses at Times 5 and 6. Students' responses to the open-ended question (i.e., "In a few sentences, please tell us how you currently feel about the online version of this course") were coded and scored to identify positive and non-positive (i.e., negative or neutral) aspects of their newly online CURE courses. If a student's comment contained any positive wording or expression, the response was coded as 1; otherwise, it was coded as 0 .

An example of a positive perspective on online science learning during COVID-19 was "I think it's going fine. The professor's slides are pretty well illustrated, enough to understand the content." An example of a non-positive perspective on online science learning was "Going online is annoying for all classes but for this one it's particularly disappointing since we were planning projects for weeks before break that we can't do anymore." Some students expressed mixed feelings about the online version of the course. For instance, one student stated that "I feel less interested in the class than before, maybe due to the transition online that made it impossible for us to complete our individual projects. I think Dr. XX [the instructor] did pretty well in finding activities for us to do online." Students responding in this way were given a score of 1 on this variable because they identified at least some positive aspects of the current course. Two researchers independently coded and scored all students' comments. The intercoder agreements were 0.96 and 1.00 at Times 5 and 6, respectively. All disagreements were resolved through discussion. Students' online science learning perspective scores were calculated by averaging the scores of Times 5 and 6.

\subsubsection{Meaning Making (Time 7)}

In the post-survey administered at Time 7, we assessed students' meaning making in three ways at two levels, namely meaning making in the course (at the contextual level), meaning making during in-person CUREs (at the situational level), and meaning making during online-transitioned CUREs (at the situational level). Meaning making in the course was assessed with four items from Wang (2019) rationale generation orientation scale. Internal consistency reliability was satisfactory in the present study (Cronbach's alpha coefficient $=0.86$ ). A sample item is: "In this course, I strived to make whatever I was learning as useful as possible." Single-item measures were used to assess students' meaning making during in-person CUREs ("During the in-person lab before Spring Break, I was able to see the connections between learning and my academic or professional goals") and meaning making during online-transitioned CUREs ("During the online course after Spring Break, I was able to see the connections between learning and my academic or professional goals"). Scale points ranged from 1 "never" to 5 "always" (Note that the online transition happened to coincide with Spring Break, so students tended to use "Spring Break" as shorthand for the change).

\subsection{Analysis}

To explore how students perceived the learning environment shift due to COVID-19 (i.e., RQ1), we first assessed their situational interest, challenge, and frustration across five time points from Week 4 (Time 2) to Week 14 (Time 6) in a 15week semester. Repeated measures ANOVA was used to examine the changes in situational interest, challenge, and frustration across four time points of the semester, two before (Times 2 and 3) transitioning online, and two after (Times 5 and 6). All dependent variables were found not to violate the assumptions of normality and sphericity. To investigate individual factors influencing the changes in situational interest, a repeated measures ANCOVA was conducted with situational meaning making during in-person (Times 2 and 3 average) and onlinetransitioned CUREs (Times 5 and 6 average) as independent variables, initial individual interest and meaning making in the course as covariates, and levels of situational interest as the dependent variable. To further understand the psychological mechanism of meaning making's impact on students' situational interest, we also tested a mediating effect of positive perspectives on online-transitioned CUREs.

\section{RESULTS}

\subsection{Students' Interest Decreased After Moving Courses Online Due to COVID-19}

As shown in Figure 1, students demonstrated a relatively high level of situational interest in the CURE classrooms at the beginning of the semester, and the level of interest remained steady until the university announced courses would be taught online due to the COVID-19 pandemic. After moving the CURE courses fully online, there was a sharp drop in the level of situational interest. Whereas, we observed a slight rise in the level of situational interest at the end of the semester across courses, it did not reach the same level that it was during the first half of the semester.

To examine whether the changes in situational interest before and after transitioning online were significant, we conducted repeated measures ANOVA using the data of students who had completed situational surveys at Times 2, 3, 5, and 6 ( $n$ $=22$ ). We found significant differences in situational interest across the four time points $\left[F_{(3,63)}=16.24, p<0.001, \eta^{2}=\right.$ 0.44]. Pairwise comparisons suggested that levels of situational interest in online science learning after the online transition were lower than those before the transition. There was no significant difference in situational interest between Times 2 and $3(p=$ $\left.0.23^{1}\right)$. Similarly, no difference in situational interest was found between Times 5 and $6(p=0.65)$.

In terms of the level of challenge, students reported moderate levels of challenge across the whole semester. No significant difference was found across Times $2,3,5$, and $6\left[F_{(3,63)}=2.37, p\right.$ $=0.08$ ]. Students' self-reported level of frustration was relatively low as the mean of frustration at Time 2 was 3.04 and a score of 4 indicates that the level of frustration is "about right;" however, there was a steady increase in the first half of the semester that peaked just as courses were transitioning online. A gradual decline in feelings of frustration was observed after the online transition. Although the result of repeated measures ANOVA suggested that there were significant differences in frustration

${ }^{1}$ Dunn-Sidak correction was used for multiple comparisons in the current study. 


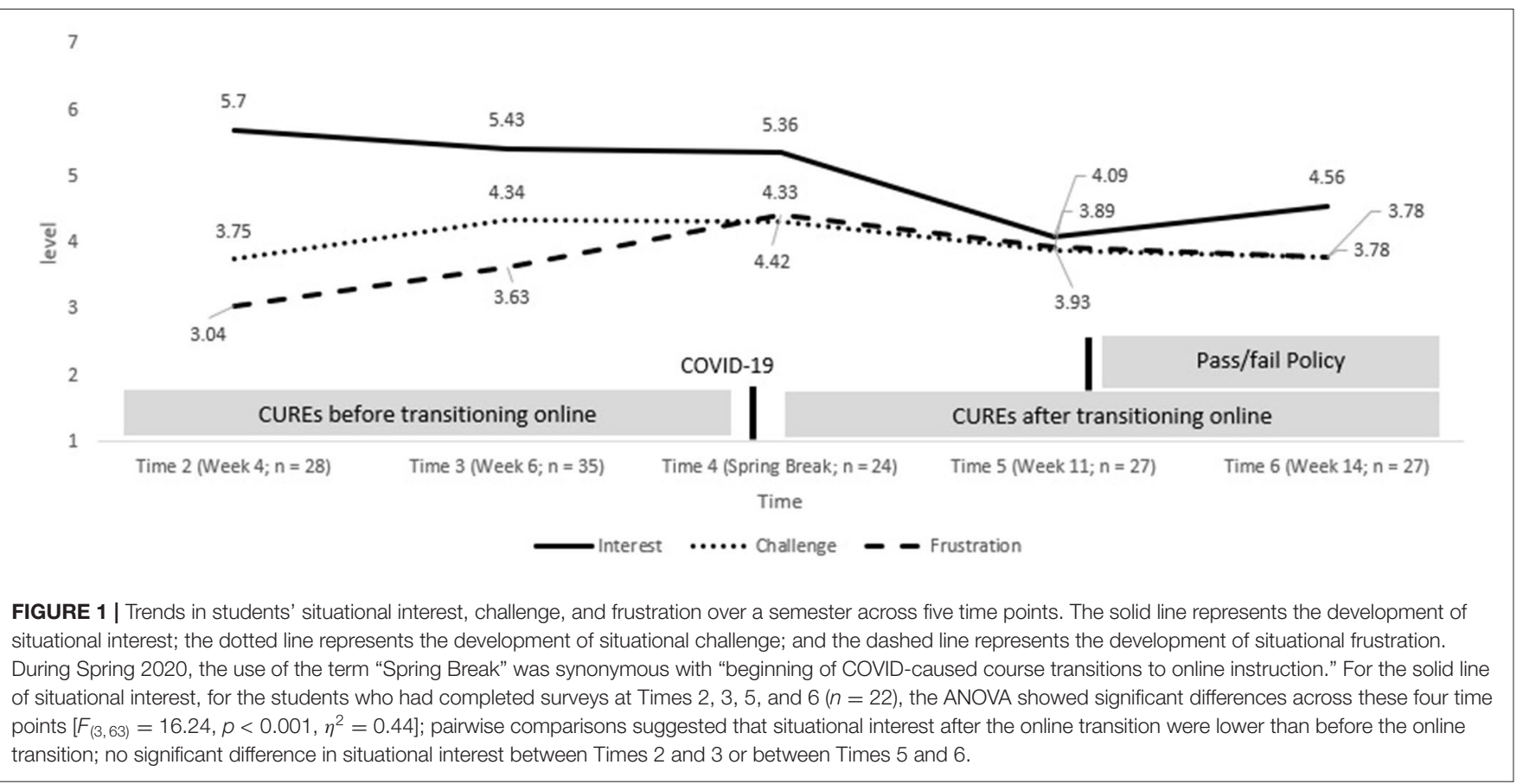

across the four time points $\left[F_{(3,63)}=3.15, p=0.03, \eta^{2}=0.13\right]$, post-hoc tests with Dunn-Sidak correction did not detect any differences between any two time points.

\subsection{Meaning Making Helped Mitigate the Decline in Situational Interest}

As previously stated, students' overall level of situational interest dropped dramatically after moving the CURE courses online. Since we found no significant difference in situational interest within in-person CUREs and online-transitioned CUREs, we decided to reduce the number of time points from four to two, which may help increase the statistical power as the student sample size increased from 22 to 29. Specifically, we calculated a "before transitioning online" score by averaging the scores of Times 2 and 3 and an "after transitioning online" score by averaging the scores of Times 5 and 6 . Repeated measures analysis showed that students' self-reported situational interest after transitioning online was significantly lower than the situational interest before transitioning online, $F_{(1,28)}=38.69, p<0.01$, $\eta^{2}=0.58$.

To investigate factors influencing the changes in situational interest, we added the three variables of: (a) meaning making in the course; (b) meaning making during in-person CUREs; and, (c) meaning making during online-transitioned CUREs, as well as the initial individual interest variable into the repeated measures model. Although the three meaning making variables were positively correlated with each other $(r=0.52-0.61)$, the range of variance inflation factors (VIF) was between 1.69 and 1.97, suggesting that some multicollinearity (i.e., overlap among variables) was present but not enough to cause problems (O’brien, 2007).

After controlling for initial individual interest and meaning making in the course, we found a significant interaction between meaning making during online-transitioned CUREs and time points, $F_{(4,13)}=5.41, p=0.009, \eta^{2}=0.63$. This result suggests that meaning making during onlinetransitioned CUREs significantly influenced the changes in situational interest. None of the remaining interaction effects were significant, including the interaction between meaning making in course (i.e., contextual meaning making) and time points $\left[F_{(1,13)}=1.46, p=0.248\right]$, the interaction between meaning making in in-person CUREs and time points $\left[F_{(3,13)}=0.57, p=0.648\right]$, and the interaction between individual interest and time points $\left[F_{(1,13)}=\right.$ $0.38, p=0.548]$.

To better understand the interaction effect between meaning making during online-transitioned CUREs and time points (i.e., before and after transitioning online), we identified two groups of students from the dataset based on their responses to the item of meaning making during online-transitioned CUREs. Specifically, students who self-reported "never" or "sometimes" seeing the connections between learning and their academic or professional goals during the online course were labeled as the low meaning making group; in contrast, students who selfreported "always" or "most of the time" were labeled as the high meaning making group.

After shifting online and to Pass-Fail grading, the low meaning making group had a steeper decline in situational interest compared to the high meaning making group (see Figure 2). This result suggests that situational meaning making (i.e., post-shifts) may have buffered against the negative effects of transitioning online on students' learning experiences. Figure 3 shows the students' situational interest over a semester was higher for the high meaning making group compared the low meaning making group, which further supports the result of repeated measures ANCOVA from Figure 2. 


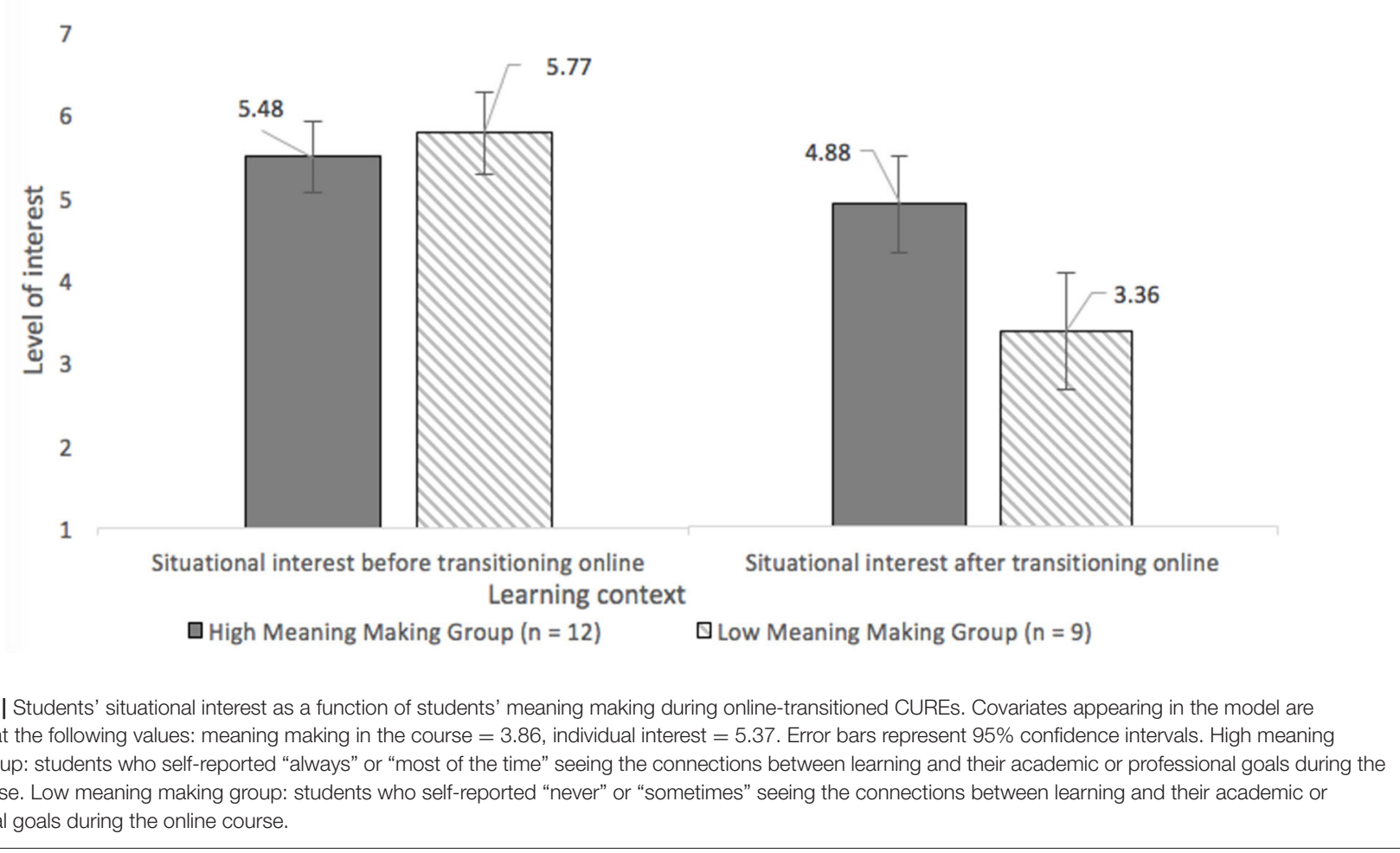

FIGURE 2 | Students' situational interest as a function of students' meaning making during online-transitioned CUREs. Covariates appearing in the model are evaluated at the following values: meaning making in the course $=3.86$, individual interest $=5.37$. Error bars represent $95 \%$ confidence intervals. High meaning making group: students who self-reported "always" or "most of the time" seeing the connections between learning and their academic or professional goals during the online course. Low meaning making group: students who self-reported "never" or "sometimes" seeing the connections between learning and their academic or professional goals during the online course.

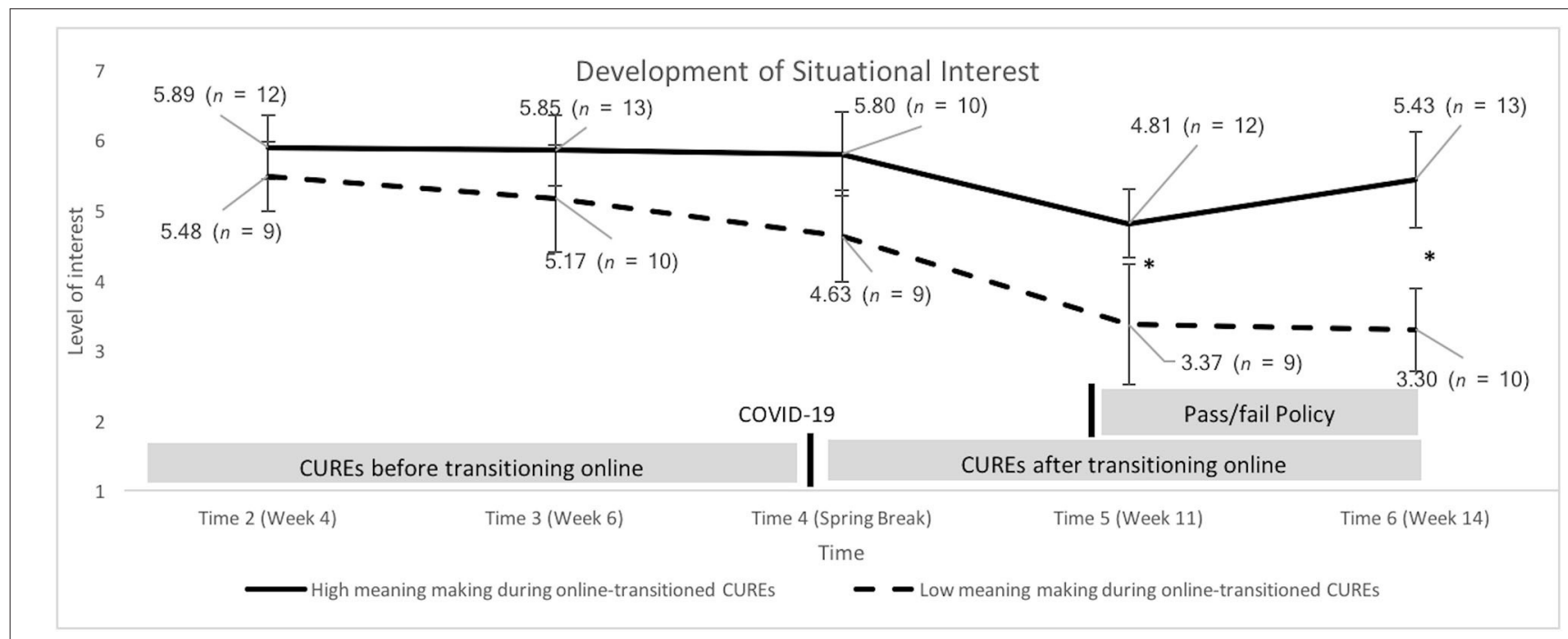

FIGURE 3 | Trends in students' situational interest for the high meaning making group and the low meaning making group during online-transitioned CUREs. Error bars represent $95 \%$ confidence intervals; astericks $\left(^{*}\right)$ represent significant group differences with $p<0.05$.

\subsection{Positive Perspectives on Online-Transitioned CUREs Mediated the Impact of Meaning Making During Online-Transitioned CUREs on Student Interest}

To further understand the psychological mechanism of student meaning making's impact on students' situational interest, we tested a mediating effect of attitudes toward their onlinetransitioned CUREs. Before testing the mediating model, we first checked the bivariate correlation coefficients among variables (see Table 2). All correlations were statistically significant and in the expected direction, which indicated that the data is appropriate for mediation analysis. We then continued to build a mediating model to examine the relationships among these variables. 
To examine the degree to which positive perspectives on online-transitioned CUREs mediated the impact of meaning making on student situational interest, we employed a series of regression analyses. Based on the procedure outlined by Baron and Kenny (1986), we first tested the direct effect of meaning making on students' situational interest after transitioning online. After controlling for students' pre-COVID19 situational interest, meaning making was still significantly associated with students' situational interest after transitioning online (standardized coefficients $\beta=0.625, t=5.14, p<0.001$ ). The path from meaning making to positive perspectives on the online portion of their CUREs (i.e., the mediating variable) was also significant, with a standardized beta of $0.587(t=$ 3.64, $p=0.001$ ). Finally, the path from meaning making to situational interest after transitioning online was significant $(t$ $=3.09, p=0.005$ ); however, the value of the standardized beta reduced from 0.625 to 0.361 . The mediation model is shown in Figure 4.

TABLE 2 | Descriptive statistics and partial correlations among the variables of interest $(n=27)$.

\begin{tabular}{lcrrrrr}
\hline & $\mathbf{1}$ & $\mathbf{2}$ & $\mathbf{3}$ & Range & Mean & SD \\
\hline $\begin{array}{l}\text { 1. Meaning making during } \\
\text { online-transitioned CUREs }\end{array}$ & - & & $1-5$ & 3.22 & 1.22 \\
$\begin{array}{l}\text { 2. Positive perspectives on } \\
\text { online-transitioned CUREs }\end{array}$ & $0.60^{* *}$ & - & $0-1$ & 0.65 & 0.41 \\
$\begin{array}{l}\text { 3. Student interest after transitioning } \\
\text { online }\end{array}$ & $0.74^{\star \star *}$ & $0.78^{\star \star *}$ & - & $1-7$ & 4.23 & 1.35 \\
\hline
\end{tabular}

Scale ranges for meaning making and student interest are consistent with the original publication. ${ }^{* *} p<0.01,{ }^{* * *} p<0.001$.
This result suggests that the relationship between meaning making during online-transitioned CUREs and situational interest after transitioning online is partially mediated by students' positive perspectives on online-transitioned CUREs, after controlling for pre-COVID-19 situational interest. Bootstrapped mediation analyses with 5,000 samples also supported the partial mediating effect of positive perspectives on online-transitioned CUREs (indirect effect $=0.299,95 \%$ C.I. $=[0.120,0.470], p=0.004)$. During online-transitioned CUREs, positive perspectives on the transitioned CUREs explained about $42.7 \%$ of the total effect of meaning making on situational interest.

\section{DISCUSSION}

We investigated how students' situational interest changed over the Spring 2020 semester within the context of several CUREs and the shift to online learning. The present study contributes to our understanding of how abrupt, unexpected changes in college science courses impact student motivation and interest, specifically due to the outbreak of COVID-19. Our findings provide preliminary insight about how we can help students stay engaged in their education when facing unexpected challenges and obstacles in learning.

In the current study, one finding was that students' situational interest dropped significantly when their CURE courses shifted from in-person instruction to online instruction (see Figure 1). For instance, students expressed disappointment for losing the opportunity to carry out their planned laboratory experiments. But for students who were able to find sudden online learning to be personally meaningful, another finding was that they were able to maintain a similar level of situational interest when measured prior to the rapid course transition (see Figure 2). Finally, the

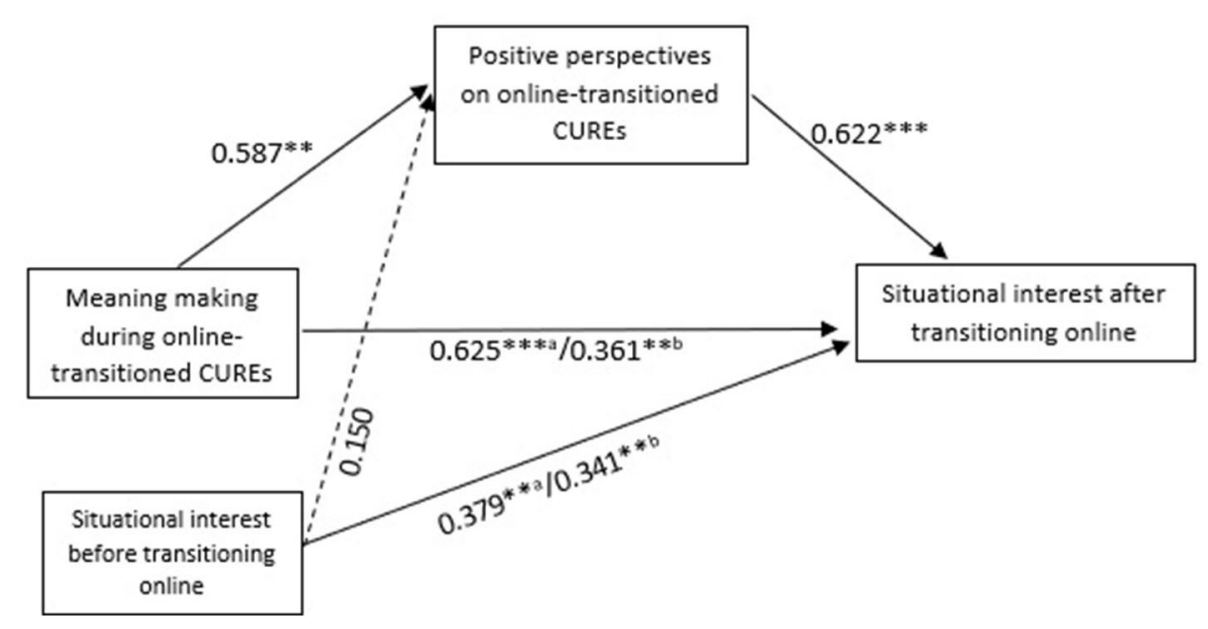

FIGURE 4 | The mediation model with standardized regression coefficients. Student meaning making during online-transitioned CUREs serves as the independent variable, positive perspectives on online-transitioned CUREs is the mediating variable, and situational interest after transitioning online is the dependent variable. "a" is the standardized $\beta$ before including the mediating variable. "b" is the standardized $\beta$ after including the mediating variable. All simple linear regression models include students' situational interest before transitioning online as a controlled variable. ${ }^{\star \star} p<0.01,{ }^{* \star *} p<0.001$. 
high meaning making group was more likely to express positive perspectives on online learning as compared to the low meaning making group. For example, for the high meaning making group there was a $92 \%$ rate of reporting a positive feeling within the context of online learning; in contrast, there was only a $35 \%$ rate for the low meaning making group.

This study of college student meaning making during the COVID-19 transition to online learning adds to the growing body of research that indicates the positive effects of meaning making on student learning (Hidi and Renninger, 2006; Hulleman et al., 2008, 2017; Heddy et al., 2017; Canning et al., 2018; Wang, 2019) and appears to be one of the first attempts to examine the influence of meaning making on student learning at this time of national and international crisis caused by COVID-19.

In terms of implications for practice, one question from the COVID-19 transition is how can we promote student meaning making in instances where students are challenged by external events that diminish their educational experience? Utility-value intervention has been confirmed to be an effective approach to promote student meaning making by a number of correlational and experimental studies (Hulleman et al., 2010, 2017; Canning et al., 2018). In those studies, the intervention was manipulated through a writing task in which participants are asked to explain either how the learning materials are relevant to their lives or why the learning tasks are important or useful to them. A recent study showed that simply providing students with opportunities to generate rationales for their learning behaviors could also help students identify the personal meaning of learning (Wang, 2019). In that study, students in the intervention group spent, on average, $112 \mathrm{~s}$ on generating rationales, which significantly enhanced their motivation with a decent effect size. It is feasible to conduct the same intervention in real classrooms. For example, instructors could give students $3 \mathrm{~min}$ to write down their reasons for taking the course at the start of each lecture. This may help students discover personal significance for completing such activities. In addition to utility-value intervention, evidence from self-determination theory research suggests a couple of other approaches to foster students meaning making, such as providing rationales (Reeve et al., 2002) and facilitating autonomy orientation of students (Ryan and Deci, 2017). When people have to do some activities that are not intrinsically motivated, providing a meaningful rationale can help them identify the value of doing those activities (Deci et al., 1994; Reeve et al., 2002; Jang, 2008; Legault et al., 2011). Autonomy orientation helps to explain why some people are more healthy, effective, and happy than others even when they are in the same social context (Ryan and Deci, 2017). It describes the degree to which people orient toward their environments by treating them as sources of relevant information (Ryan and Deci, 2017). A strong autonomy-oriented person tends to engage in challenging situations more congruently and openly and with less defensive responding.

Although we observed a decline in student interest in general after the CURE courses moved online and shifted to Pass-Fail grading, the rates of decline varied across students. It is intriguing that being able to see connections between their course activities and personal goals may help mitigate the impact of the rapid transition online on student interest; however, there may be alternative explanations based on other theoretical frameworks that future research needs to explore.

Student meaning making was examined at both contextual and situational levels. As expected, student situational interest was mainly influenced by student meaning making at the situational level, which is consistent with the framework of hierarchical model of motivation (Vallerand, 1997; Vallerand and Ratelle, 2002). Different from situational meaning making (i.e., meaning making after transitioning online), we did not detect significant association between contextual meaning making (i.e., meaning making in the course overall) and situational interest, it is possible that the rapid changes in course activities and learning environments amplify the differences between students' learning experiences at the contextual and situational levels. This limitation should be explored in future research.

It is important to note that our findings are situated in the context of laboratory-based CURE courses at a single research university. Furthermore, the university moved to a system-wide Universal Pass/Fail grading system soon after moving online, and this which could further modify students' interest, positive feelings, and experiences. This policy also limited our ability to assess course performance in terms of final grade. All four CURE courses involved in the current study were also elective courses and students reported initially high motivations to learn. Together, these common variables may explain the low variances in student interest (see Figure 1). Moreover, the findings about the changes in situational interest need to be interpreted with caution, as we do not have a comparison group showing how students' situational interest evolves in a regular CURE context. Further quasi-experimental investigations are needed to determine the impact of unexpected online transition on the development of situational interest.

Additionally, our small sample size did not allow us to employ a more advanced technique, such as latent growth modeling, to estimate longitudinal growth trajectories of situational interest. Instead, we employed repeated measures ANOVA and repeated measures ANCOVA, which allowed us to gain insights into the current study's research questions. Finally, several variables, namely situational challenge, situational frustration, and meaning making in online science learning, were assessed with single-item measures. Therefore, internal consistency reliabilities of these variables were not available in the current study. Although previous research suggests that singleitem measures generally perform well when gauging a holistic impression or a global perception (Youngblut and Casper, 1993), as is the case here, multiple-item scales would be necessary if researchers intend to obtain better estimates of the constructs by specifying the measurement errors associated with them.

\section{CONCLUSIONS}

We documented the impacts of rapidly transitioning inperson laboratory-based CUREs into fully online courses. This unprecedented situation provides insights into how teaching 
practices and course activities interact with student expectations and perspectives in a learning environment. We observed a drop in the level of student situational interest after moving the CUREs online due to the pandemic of COVID-19. We further found that meaning making may help explain differential student responses to the disrupted course plans. Students who were able to make meaningful connections between the learning activities and their personal academic or career goals were more likely to view the online-transitioned learning experience more positively. In turn, these attitudes helped students maintain a higher level of situational interest despite a mid-semester shift to fully remote learning due to COVID-19. These results provide insight into how to help students manage their own resilience during unexpected learning conditions and obstacles.

\section{DATA AVAILABILITY STATEMENT}

The raw data supporting the conclusions of this article will be made available by the authors, without undue reservation.

\section{ETHICS STATEMENT}

The studies involving human participants were reviewed and approved by Yale University Institution Review Board. The patients/participants provided their written informed consent to participate in this study.

\section{REFERENCES}

Auchincloss, L. C., Laursen, S. L., Branchaw, J. L., Eagan, K., Graham, M., Hanauer, D. I., et al. (2014). Assessment of course-based undergraduate research experiences: a meeting report. CBE Life Sci. Educ. 13, 29-40. doi: 10.1187/cbe.14-01-0004

Baron, R. M., and Kenny, D. A. (1986). The moderator-mediator variable distinction in social psychological research: conceptual, strategic, and statistical considerations. J. Pers. Soc. Psychol. 51:1173. doi: 10.1037/0022-3514.51.6.1173

Canning, E. A., Harackiewicz, J. M., Priniski, S. J., Hecht, C. A., Tibbetts, Y., and Hyde, J. S. (2018). Improving performance and retention in introductory biology with a utility-value intervention. J. Educ. Psychol. 110:834. doi: $10.1037 /$ edu0000244

Corwin, L. A., Dolan, E. L., Graham, M. J., Hanauer, D. I., and Pelaez, N. (2018). The need to be sure about cures: discovery and relevance as critical elements of cures for nonmajors. J. Microbiol Biol. Educ. 19, 1-13. doi: 10.1128/jmbe.v19i3.1683

Deci, E. L., Eghrari, H., Patrick, B. C., and Leone, D. R. (1994). Facilitating internalization: the self-determination theory perspective. J. Pers. 62, 119-142. doi: 10.1111/j.1467-6494.1994.tb00797.x

Dolan, E. L. (2016). "Course-based undergraduate research experiences: current knowledge and future directions," Paper Commissioned for the Committee on Strengthening Research Experiences for Undergraduate STEM Students Board on Science Education (Washington, DC: Division of Behavioral and Social Sciences and Education Board on Life Sciences, Division of Earth and Life Studies).

Graham, M. J., Frederick, J., Byars-Winston, A., Hunter, A.-B., and Handelsman, J. (2013). Increasing persistence of college students in stem. Science 341, 1455-1456. doi: 10.1126/science. 1240487

Hanauer, D. I., Graham, M. J., Betancur, L., Bobrownicki, A., Cresawn, S. G., Garlena, R. A., et al. (2017). An inclusive research education

\section{AUTHOR CONTRIBUTIONS}

$\mathrm{CW}, \mathrm{MB}, \mathrm{AB}$, and MG designed the study and collected the data. $\mathrm{CW}, \mathrm{MB}$, and $\mathrm{MG}$ formulated the hypotheses. CW and MB coded the qualitative data. CW performed the statistical analyses and drafted the manuscript. $\mathrm{CW}, \mathrm{MB}, \mathrm{AB}, \mathrm{DH}$, and $\mathrm{MG}$ revised and edited the manuscript. All authors contributed to the article and approved the submitted version.

\section{FUNDING}

This work was made possible through two National Science Foundation (NSF) Improving Undergraduate STEM Education grants: NSF-DUE \# 1856150 and NSF-DUE \# 2027658.

\section{ACKNOWLEDGMENTS}

We thank the instructors of the four CURE courses for their responses and dedication to STEM education reform. Special acknowledgment to all of the students who participated through survey responses. We are grateful to William Trochim and Philip M. Reeves for their feedback on an earlier version of the manuscript.

\section{SUPPLEMENTARY MATERIAL}

The Supplementary Material for this article can be found online at: https://www.frontiersin.org/articles/10.3389/feduc. 2020.590738/full\#supplementary-material

community (IREC): impact of the sea-phages program on research outcomes and student learning. Proc. Natl. Acad. Sci. U.S.A. 114, 13531-13536. doi: $10.1073 /$ pnas.1718188115

Harackiewicz, J. M., Durik, A. M., Barron, K. E., Linnenbrink-Garcia, L., and Tauer, J. M. (2008). The role of achievement goals in the development of interest: reciprocal relations between achievement goals, interest, and performance. J. Educ. Psychol. 100:105. doi: 10.1037/0022-0663. 100.1.105

Heddy, B. C., Sinatra, G. M., Seli, H., Taasoobshirazi, G., and Mukhopadhyay, A. (2017). Making learning meaningful: Facilitating interest development and transfer in at-risk college students. Educ. Psychol. 37, 565-581. doi: 10.1080/01443410.2016.1150420

Hernandez, P. R., Hopkins, P. D., Masters, K., Holland, L., Mei, B. M., RichardsBabb, M., et al. (2018). Student integration into stem careers and culture: a longitudinal examination of summer faculty mentors and project ownership. CBE Life Sci. Educ. 17:ar50. doi: 10.1187/cbe.18-02-0022

Hidi, S., and Renninger, K. A. (2006). The four-phase model of interest development. Educ. Psychol. 41, 111-127. doi: 10.1207/s15326985ep4102_4

Hulleman, C. S., Durik, A. M., Schweigert, S. B., and Harackiewicz, J. M. (2008). Task values, achievement goals, and interest: an integrative analysis. J. Educ. Psychol. 100:398. doi: 10.1037/0022-0663.100.2.398

Hulleman, C. S., Godes, O., Hendricks, B. L., and Harackiewicz, J. M. (2010). Enhancing interest and performance with a utility value intervention. J. Educ. Psychol. 102:880. doi: 10.1037/a0019506

Hulleman, C. S., Kosovich, J. J., Barron, K. E., and Daniel, D. B. (2017). Making connections: replicating and extending the utility value intervention in the classroom. J. Educ. Psychol. 109:387. doi: 10.1037/edu0000146

Jang, H. (2008). Supporting students' motivation, engagement, and learning during an uninteresting activity. J. Educ. Psychol. 100:798. doi: 10.1037/ a0012841 
Legault, L., Gutsell, J. N., and Inzlicht, M. (2011). Ironic effects of antiprejudice messages: how motivational interventions can reduce (but also increase) prejudice. Psychol. Sci. 22, 1472-1477. doi: 10.1177/0956797611427918

O’brien, R. M. (2007). A caution regarding rules of thumb for variance inflation factors. Qual. Quant. 41, 673-690. doi: 10.1007/s11135-006-9018-6

Reeve, J., Jang, H., Hardre, P., and Omura, M. (2002). Providing a rationale in an autonomy-supportive way as a strategy to motivate others during an uninteresting activity. Motiv. Emot. 26, 183-207. doi: 10.1023/A:1021711629417

Renninger, K. (2010). "Working with and cultivating the development of interest, self-efficacy, and self-regulation," in Innovations in Educational Psychology: Perspectives on Learning, Teaching, and Human Development, eds D. Preiss and R. Sternberg (New York, NY: Springer Publishing Company), 107-138.

Ryan, R. M., and Deci, E. L. (2017). Self-Determination Theory: Basic Psychological Needs in Motivation, Development, and Wellness. New York, NY: Guilford Publications. doi: 10.1521/978.14625/28806

Schraw, G., and Lehman, S. (2001). Situational interest: a review of the literature and directions for future research. Educ. Psychol. Rev. 13, 23-52. doi: 10.1023/A:1009004801455

Vallerand, R. J. (1997). "Toward a hierarchical model of intrinsic and extrinsic motivation," in Advances in Experimental Social Psychology, Vol. 29, ed M. P. Zanna (San Diego, CA: Elsevier), 271-360. doi: 10.1016/S0065-2601(08)60019-2

Vallerand, R. J., and Ratelle, C. F. (2002). "Intrinsic and extrinsic motivation: a hierarchical model," in Handbook of Self-Determination Research, eds
E. L. Deci and R. M. Ryan (Rochester, NY: University of Rochester Press), 37-63.

Wang, C. (2019). "Learning is not always fun, but it is fine" effects of rationale generation on autonomous motivation and learning in uninteresting but required academic activities (Ph.D. thesis). Purdue University Graduate School, West Lafayette, IN, United States. doi: 10.25394/PGS.99 55214.v1

Wolters, C. A., and Pintrich, P. R. (1998). Contextual differences in student motivation and self-regulated learning in Mathematics, English, and Social studies classrooms. Instr. Sci. 26, 27-47.

Youngblut, J. M., and Casper, G. R. (1993). Focus on psychometrics singleitem indicators in nursing research. Res. Nurs. Health 16, 459-465. doi: $10.1002 /$ nur.4770160610

Conflict of Interest: The authors declare that the research was conducted in the absence of any commercial or financial relationships that could be construed as a potential conflict of interest.

Copyright (c) 2020 Wang, Bauer, Burmeister, Hanauer and Graham. This is an openaccess article distributed under the terms of the Creative Commons Attribution License (CC BY). The use, distribution or reproduction in other forums is permitted, provided the original author(s) and the copyright owner(s) are credited and that the original publication in this journal is cited, in accordance with accepted academic practice. No use, distribution or reproduction is permitted which does not comply with these terms. 